\title{
Plantar Fasciitis in Diabetic Foot Patients: Risk Factors, Pathophysiology, Diagnosis, and Management
}

This article was published in the following Dove Press journal:

Diabetes, Metabolic Syndrome and Obesity: Targets and Therapy

\author{
Karim Gariani (D) \\ Felix WA Waibel (D) ${ }^{2}$ \\ Arnd F Viehöfer ${ }^{2}$ \\ Ilker Uçkay ${ }^{3}$
}

'Service of Endocrinology, Diabetes, Hypertension and Nutrition, Geneva University Hospitals, Geneva, Switzerland; ${ }^{2}$ Foot and Ankle Service, Department of Orthopedic Surgery, Balgrist University Hospital, Zurich, Switzerland; ${ }^{3}$ Unit for Clinical and Applied Research, Balgrist University Hospital, Zurich, Switzerland
Correspondence: Karim Gariani Endocrinology, Diabetes, Hypertension and Nutrition, Geneva University Hospitals, Geneva, Switzerland Email Karim.gariani@hcuge.ch

\begin{abstract}
Plantar fasciitis (PF) is a common degenerative disorder and a frequent cause of heel pain, mostly affecting patients in their fourth and fifth decades. Diabetic patients are particularly at risk due to the presence of common risks and co-morbidities such as obesity or a sedentary lifestyle. The diagnosis of PF is mainly clinical. Imaging is not recommended for the initial approach. The initial management is conservative and should include physiotherapy, off-loading, stretching exercises, and nonsteroidal anti-inflammatory drugs. Glucocorticoid injections or surgery is an option at a later stage in recalcitrant cases. The overall management of PF does not differ between patients with diabetic foot problems and non-diabetic patients, although the details can differ. This narrative review summarizes the state of the art in terms of the risk factors, pathophysiology, diagnosis, assessment, and management of PF in diabetic patients.
\end{abstract}

Keywords: plantar fasciitis, diabetic foot, management, epidemiology, diagnosis

\section{Introduction}

$\mathrm{DM}$ is an epidemic disease that affects 425 million people worldwide and it is predicted to increase by $48 \%$ to 629 million patients by $2045 .^{1}$ It is associated with a multitude of chronic impairments related to micro- and macroangiopathic involvement and polyneuropathy. These comprise cardiovascular complications, stroke, retinopathy, nephropathy, adhesive capsulitis, Dupuytren's contracture, crystalinduced arthritis, and PF. ${ }^{2,3}$ The occurrence of these disorders is associated with the duration and control of DM. ${ }^{4}$ Neuropathic complications or previous foot ulcers are associated with an increased prevalence of PF in diabetic patients. ${ }^{5}$ However, it remains unclear whether PF is directly imputable to DM itself, its hyperglycemic state, or whether PF only shares common comorbidities and risk factors such as obesity, alcohol consumption, and active smoking. In terms of pathogenicity, metabolic disturbances are known to impair the conformation and mechanical features of tendons, ${ }^{6}$ especially in metatarsophalangeal joints, the plantar fascia, and the Achilles tendon, by forming complex biomechanical structures. ${ }^{7}$ They also play a role in the pathological distribution of plantar pressure on the foot; a condition that is frequently observed in diabetic patients as they tend to have increased forefoot pressure and, therefore, subsequently develop the corresponding lesions. $^{8-11}$

$\mathrm{PF}$ is among the most frequent causes of activity-enhanced foot pain in the adult population. The overall prevalence of this local, non-infectious inflammation is estimated to be $10 \%$. The vast majority of patients are initially assessed by general 
practitioners. To cite an example, in the United States, approximately one million people consult a doctor each year resulting in a final diagnosis of $\mathrm{PF}^{12}$ The peak incidence occurs in individuals between 40 and 60 years of age. ${ }^{13}$ The occurrence of PF is not associated with participation in sports or with gender. A recent and large cohort study that evaluated the prevalence of $\mathrm{PF}$ in 720,000 diabetic patients found that the incidence of $\mathrm{PF}$ was $0.85 \%{ }^{14}$ More specifically, the incidence of $\mathrm{PF}$ was $0.80 \%$ in non-diabetic adults, $1.31 \%$ in type 2 diabetics, and $0.92 \%$ in type 1 diabetic adults. In this survey, the group with type 2 diabetes had a significantly higher incidence of PF than those with type 1 (or no diabetes), while the difference between the non-diabetics and the type 1 diabetics was not statistically significant. This was still the case after adjustment for the BMI and gender. ${ }^{14}$ In this short narrative review, we address the state of the art regarding the risk factors, pathophysiology, diagnosis, assessment, and management of PF in adult diabetic patients.

\section{Methods}

All of the authors performed a scientific literature search using PubMed and Google (Scholar) for publications regarding $\mathrm{PF}$ in adult diabetic patients using the MeSH terms "plantar fasciitis", in combination with "diabetes" or "diabetic foot", in English, French, or German up to 31 July 2019 without restriction of the setting, the medical specialty, or the time. We manually searched the references of the retrieved papers for further reports. We excluded reports with underlying osteosynthesis devices or previous plantar surgeries for any reason.

\section{Epidemiological Risk Factors and the Pathogenesis of Plantar Fasciitis}

No exact (single) etiology for PF has been shown, and PF is most likely a multifactorial disease. It has been associated epidemiologically with age, obesity, a sedentary lifestyle, flat (planus) or high-arched (cavus) feet, gastrocnemius contracture, long-distance runners, and individuals who have to stand a lot for their work. ${ }^{12,15-17}$ A systematic review of 51 studies found that a BMI $>27 \mathrm{~kg} / \mathrm{m}^{2}$ was the only significant factor associated with $\mathrm{PF} .{ }^{18}$ Of note, $\mathrm{PF}$ has only rarely been associated epidemiologically with systemic rheumatic diseases such as spondyloarthropathy and reactive arthritis of fibromyalgia. Infectious PF, without any other localization of infection in diabetic foot, is very rare.
Some research groups favor a degenerative origin. $\mathrm{PF}$ is characterized primarily by degeneration of the plantar fascia as a result of repetitive micro-tears that give rise to a local inflammatory response without systemic repercussions. Shortening of the gastrocnemius-soleus complex may play a crucial role in the development of PF. Other research groups have stressed the apparent involvement of metabolic factors in the pathogenesis of PF, along with mechanical overuse. This could particularly be the case in DM patients. In this view, PF in DM foot is linked to advanced glycation end-products (AGEs). ${ }^{19,20}$ Indeed, AGEs induce collagen crosslinking, ultimately leading to altered collagen structures and secondary mechanical dysfunction. In vitro, glycation disrupts the organization of collagen, resulting in an irregular fibril density and morphology. Electron microscopy has revealed a reduced density of tenocytes and fibroblasts along with an increased density of collagen. Of note, AGEs are increased in DM. Their presence has been directly associated with increased plantar fascial or Achilles tendon thickness in diabetic subjects; in contrast to non-diabetic subjects. ${ }^{21,22}$ Hyperglycemia itself can modify redox homeostasis, particularly the polyol pathway, thereby leading to cellular edema. ${ }^{6} \mathrm{DM}$ is also associated with decreased tendon neovascularization. ${ }^{23}$ The density of capillaries per unit of surface area is reduced, thereby leading to reduced blood flow. ${ }^{24}$ This alteration could reduce vessel and nerve growth. The addition of a sensitive neuropathy and reduced nerve ingrowth decrease the distress signals and ultimately repromote tendon overuse and damage.

Distal polyneuropathy (DPN) is common in diabetic patients, with a prevalence of at least $50 \%$. DPN is defined as a loss of sensitivity beginning distally in the lower extremities that may also be characterized by pain and significant morbidity. (ref) Half of the patients are asymptomatic and therefore remain at high risk for insensate lesions to their feet. (ref) Assessment of diabetic patients at least once a year for the presence and severity of DPN is recommended. This can be performed using a graduated tuning fork $(128 \mathrm{~Hz})$, 10-g monofilament testing, or by the ankle jerk reflex. In the presence of DPN, other causes of neuropathy must be excluded, including vitamin deficiency, renal failure, or thyroid disorders. The precise contribution of DPN in the development of PF has yet to be elucidated as the available data have remained limited. Studies assessing the association have indicated that $\mathrm{PF}$ is independent of the presence of moderate to severe DPN. ${ }^{3,8}$ Clinicians should, therefore, consider PF even in the absence of clinical DPN. 
Other effects of DM, such as hypercholesterolemia, obesity, and hyperuricemia, may also play a role in PF. ${ }^{6}$ Obesity in particular contributes by means of two distinct mechanisms. First, the increased weight on the tendons promotes inflammation and structural alterations. Secondly, many adipose tissue hormones, e.g. adipokines, lipocalin-1, serum amyloid A-3, and adiponectin, can disrupt the cellular functions of chondrocytes and tenocytes; thereby potentially leading to tendon disruption. ${ }^{25,26}$ The potential role of chronic hypercholesterolemia in tendinopathies remains a matter of debate. Some studies have been able to correlate sonographic or histological tendon alterations with serum lipid levels. ${ }^{25,26}$ Small cholesterol particles may accumulate in tendons, thereby eliciting low-grade inflammation and tendon damage.$^{27}$ Finally, both asymptomatic hyperuricemia and gout are associated with DM and PF as they share common risk factors. ${ }^{28}$ Urate deposition and tophus formation can occur at various sites in the body, including the plantar fascia. Repetitive micro-trauma on these tophi may alter their interaction with the matrix and promote inflammation and consecutive tendon injury. ${ }^{6,29}$ Figure 1 provides an overview of the metabolic pathogenesis of PF, especially for diabetic foot.

\section{Pathological Pressure Redistribution in Diabetes and Plantar Fasciitis}

Anatomical alteration and pressure redistribution are important factors in the development of plantar fascia and are favored by the presence of neuropathic diabetic foot.
Anatomically, the plantar fascia is composed of three bands of compact connective tissue that arise from the medial calcaneal tubercle and that insert distally into the base of each proximal phalanx. When the plantar fascia is stretched, ${ }^{30}$ the strain consolidates the medical longitudinal arch, which then enables the foot to operate as a stiff lever for forward propulsion in conjunction with inversion in the Chopart joint line. ${ }^{31}$ This increase in plantar pressure distribution in DM patients has been observed in several studies. ${ }^{32,33}$ It appears to be related to altered proprioception that leads to instability between the long extensors and flexors of the toes, thereby causing further protrusion of the metatarsal heads and thus promoting the development of clawed toes. ${ }^{32}$ Consequently, the plantar pressure increases under the hallux and the $5^{\text {th }}$ metatarsal head, whereas the pressure under the heel decreases. ${ }^{34} \mathrm{~A}$ vicious circle sets in as the anterior pressure promotes callus formation that, in turn, intensifies the plantar pressure. Not surprisingly, elevated plantar pressure is a major contributor to plantar ulcers in diabetic and PF patients. ${ }^{5,35,36}$

\section{Diagnosis of Plantar Fasciitis (in Diabetic Foot)}

$\mathrm{PF}$ is essentially a clinical diagnosis, relying on pain localized in the inferior heel with a distinct area of tenderness that is exacerbated by walking, while it wanes with resting. The pain usually dissipates to a certain degree over the course of the day, although it can flare up after periods of prolonged standing. Upon physical examination, passive dorsiflexion of the ankle and toes (windlass test) usually

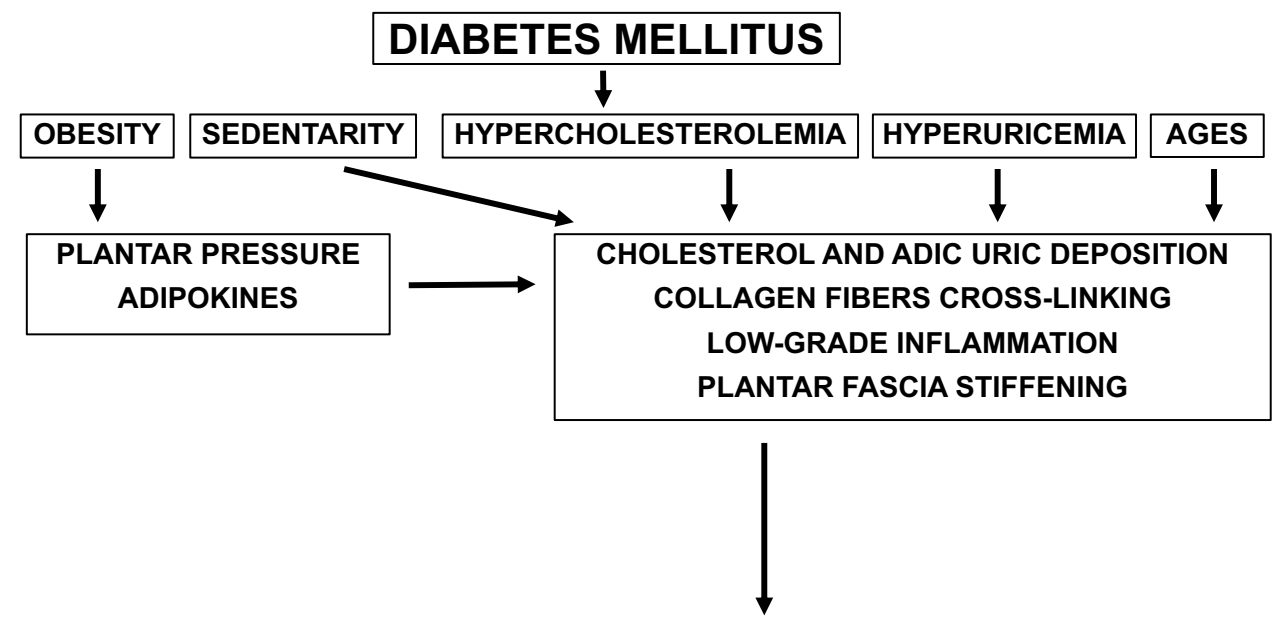

\section{PLANTAR FASCIITIS}

Figure I Proposed pathogenic mechanisms for the development of plantar fasciitis in diabetic patients. Abbreviation: AGES, Advanced glycation end products. 
induces pain. Furthermore, physicians should actively examine the gastrocnemius-soleus complex. A lack of ankle dorsiflexion beyond $10^{\circ}$ reflects shortening of the gastrocnemius-soleus complex, which is associated with PF. The differential diagnosis is extensive, but it typically comprises neurological causes such as progressive polyneuropathic pain; or compression of the first branch of the lateral plantar nerve ("Baxter neuropathy"). Soft tissue involvement can indicate retro-calcaneal non-infectious bursitis, Achilles tendinopathy, or plantar fascia rupture. Heel pain originating from the bone typically includes a history of contusion, fracture, or Haglund's syndrome, which is an entity defined by the presence of insertional Achilles tendinopathy, retrocalcaneal bursitis and calcaneal prominence (Haglund deformity).As for all diabetic foot problems, an underlying osteomyelitis should be ruled out (at least clinically), especially when the skin is altered, chronically ulcerated, and/or inflamed. ${ }^{37}$ By contrast, acute or chronic diabetic foot ischemia (without visual soft tissue necrosis) is unlikely to occur exclusively at the plantar fascia.

Blood tests are not decisive, as inflammatory markers would only be increased by concomitant systemic inflammatory disease, but not by a local (mechanically triggered) inflammation. Imaging is not required for the initial assessment of PF, although it can be helpful to rule out alternative etiologies of heel pain, especially in diabetic foot. ${ }^{38}$ Sometimes, in refractory and atypical cases, a plain X-ray may be required. Plantar fascia thickness at its calcaneal origin is suggestive of $\mathrm{PF}$, with a sensitivity of $85 \%$ and a specificity of $95 \% .{ }^{39}$ Plain X-rays can also reveal calcaneal spurs. Although international experts have questioned the diagnostic value of calcaneal spurs for the primary diagnosis of $\mathrm{PF}^{40}$ they might nonetheless be indicative of $\mathrm{PF}$ severity. ${ }^{41}$ In addition, conventional X-rays may be helpful to detect a (stress) fracture. Sonographic findings of PF comprise fascial thickening, hypoechogenicity at the calcaneal insertions, and the loss of fibrillar structures. Ultrasound may also be valuable for distinguishing PF from diabetic foot infections or tumors. The MRI characteristics of PF include thickening of the plantar fascia and increased signal on delayed T2 sequences. Out of all of the available imaging modalities, MRI is considered to be the most sensitive technique for diagnosing $\mathrm{PF}^{42,43}$

\section{Management and Therapies}

In 2010, the American College of Foot and Ankle Surgeons released an update regarding PF management. These guidelines favor a three-tiered approach ${ }^{44}$ and they are recommended for all PF patients, including those with diabetic foot problems. According to these recommendations (Figure 2), first-line treatment of PF is usually managed by a general practitioner or a diabetologist, and consists of physiotherapy, stretching exercises, over-the-counter arch supports, and oral nonsteroidal anti-inflammatory drugs. The second line includes steroid injections, orthotic devices, immobilization, off-loading, and eventually night splints. The third tier should be considered after six to twelve months of persistent PF and it comprises extracorporeal shockwave therapy (ESWT), physiotherapy, or (as a last resort) surgical intervention such as elective plantar fasciotomy.

\section{Exercises}

These recommendations are clearly of overall benefit to DM patients, and those with diabetic foot problems in particular. ${ }^{45,46}$ Exercise therapy has an important role in the overall management of diabetic foot disorders. It improves the functional capacity ${ }^{47,48}$ and endothelial functions while it reduces oxidative stress and inflammatory responses. ${ }^{49,50}$ Walking and stretching can often be performed in



Figure 2 Proposed 3 steps approach for the management of plantar fasciitis.

Abbreviations: NSAIDs, nonsteroidal anti-inflammatory drugs; ESWT, extracorporeal shockwave therapy. 
conjunction. Moreover, the foot joint range of motion (ROM) is often altered in diabetic patients due to plantar fascia stiffness, which can ultimately give rise to a rigid foot. ${ }^{51}$ Home exercise program should be proposed to diabetic patients in order to improve the ROM to prevent the development of diabetic foot complications related to the alteration of plantar pressure distribution. Indeed, a study have shown that self-care exercise can prevent the reduction of ROM in diabetic patient with and without neuropathy. Pedobarographic assessment should also be performed before and after the occurrence of PF in diabetic patients ${ }^{52}$. Another aim of stretching exercises is to reduce plantar fascia (and Achilles tendon) tension by decreasing the anatomical arch deformation and foot pronation while increasing ankle dorsiflexion. A small RCT with 19 diabetic foot patients showed that only professional active and passive ROM exercises significantly reduced plantar pressure. ${ }^{53}$ Likewise, regular exercise at home may also reduce the risk of foot ulceration and promote the functional independence of diabetic patients. Stretching techniques can also influence the outcome. Manual stretching appears to have only a limited beneficial effect on pain and foot function, as suggested by a recent systematic review. ${ }^{54}$ The benefit of manual stretching can be seen in the first four months, in contrast to active exercises performed by the patient themselves with professional guidance. ${ }^{54}$ The ideal frequency and number of prophylactic or therapeutic stretching for PF remain unknown and could be highly individual. The majority of PF cases can be managed conservatively, as only $10 \%$ require surgery. ${ }^{55,56}$

\section{Medical Therapies and Related Outcomes}

Systemic oral nonsteroidal anti-inflammatory drugs (NSAIDs) at standard doses should be considered in the absence of any contraindications, despite the limited available evidence. They can always be administered concomitant with exercise. While topical NSAIDs probably do not influence the inflammation, they could provide a degree of relief of local superficial pain. In the area of PF, we are aware of only a single small RCT of NSAIDs with 29 patients, which found non-significant improvement of pain with NSAIDs after 2 and 6 months of treatment, thus suggesting that NSAIDs could possibly result in a degree of pain relief and reduced disability in patients with $\mathrm{PF}^{55}$ The duration of treatment with NSAIDs should not exceed two to three weeks to avoid side effects, especially when there is no clinical benefit. The initial therapy also comprises rest and ice packs, as both of these can temporarily reduce pain. Of note, the application of heat appears to result in less of a benefit compared to ice. ${ }^{57}$

Local subcutaneous glucocorticoid injections should be considered if the disability persists after a month of conservative PF therapy. They usually contain a mixture of a longacting glucocorticoid and a local anesthetic, and they lead to a rapid, albeit short-term, pain relief. A combination of glucocorticoid and lidocaine appeared to be superior to lidocaine only in an RCT involving 106 patients. However, the benefit of such a combination for refractory PF disappeared after 3 months compared to lidocaine only. ${ }^{58}$ Repetitive steroid injections can lead to heel-pad atrophy and rupture of the plantar fascia. ${ }^{59,60}$ Glucose monitoring is recommended after glucocorticoid injection, and a temporary treatment adjustment may be required. A significant degree of clinical improvement is frequently observed during the first six weeks of conservative therapy. When there is a clinical response, the therapy should be pursued until the symptoms disappear. In the absence of success with this treatment, the patient should be referred to an orthopedic surgeon specialized in foot and ankle surgery, or to a rheumatologist with experience with PF.

\section{Casts, Devices, and Immobilization}

There are various types of foot orthoses, such as custommade, prefabricated, or medial arch supports. Prefabricated orthoses are usually part of the first-line therapy, whereas custom-made or medical arch supports are considered to be a second-line therapy. Over-the-counter arch supports can generally be purchased at pharmacies. However, their clinical benefits remain controversial. Compared to custommade orthoses, over-the-counter arches have been associated with early withdrawal due to lack of compliance, persistent pain, or an inability to tolerate the device (50). A recent metaanalysis included twenty studies with a total of eight types of foot orthoses for PF. ${ }^{61}$ The authors found that there was no difference in pain improvement or function between prefabricated, custom-made, or sham orthoses. ${ }^{61}$ Night splints are part of the second-line therapy. Their positive impact in $\mathrm{PF}$ remains to be proven, however. Another recent RCT (40 patients) showed no improvement with night splints compared to a home exercise program without night splints. ${ }^{62}$ Finally, cast immobilization for 4-6 weeks, or the use of a short-leg walking boot, have been suggested after failure of the first-line therapy. The level of evidence remains low, however, mainly due to the lack of RCTs. ${ }^{63}$ Symptomatic improvement with the second-tier approach should be 
observed within 2 to 3 months, and it usually happens in up to $90 \%$ of patients. ${ }^{57,64}$

\section{When Everything Fails}

The third (and last) therapeutic line is reserved for clinical failures after six to twelve months of first- and second-line therapies. Its options are ESWT and surgical plantar fasciotomy. Patients considered for surgery account for only 1 to $2 \%$ of all PF cases. ${ }^{65,66}$ They should ideally be evaluated by an orthopedic surgeon with expertise in plantar foot surgery. Various surgical techniques have been reported in the literature: endoscopic plantar fasciotomy, open plantar fascia release, open or percutaneous plantar fasciotomy, median calcaneal nerve neurolysis, and calcaneal osteotomy with resection of parts of the fascia. ${ }^{67,68}$ These options are the same when DM patients are involved. There has been a lack of RCTs to date comparing the efficacy of these various surgical procedures. The reported success rates vary between the studies, and they typically range between 50 and $90 \%{ }^{67,68}$ Currently, most experts tend to opt for an endoscopic minimally invasive surgical approach as opposed to a large open surgery, as a minimally invasive approach generally leads to a faster recovery while providing a similar degree of clinical pain relief after one year. ${ }^{69}$ The use of therapeutic ultrasound during surgery does not appear to offer any additional benefit. Rather, it in fact correlates with an increased risk of complications, ${ }^{44,70-72}$ and the exact reasons for this remain unknown. The potential complications of PF surgery comprise iatrogenic calcaneal fracture, infection, posterior tibial nerve injury, and flattening of the longitudinal arch. Diabetic patients tend to have more complications, namely surgical site infections, and especially in their feet. ${ }^{73}$

ESWT is the second option in third-line therapy for PF. It is non-invasive and it is based on shock waves produced by electromagnetic, electrohydraulic, or piezoelectric techniques. The wave transmission through pain receptors is thought to elicit a healing process by means of the release of growth factors that ultimately favor neovascularization. ${ }^{74,75}$ The level of evidence is low, and no recent studies have reported a significant clinical benefit of this method in PF treatment. ${ }^{76-78}$ An elevated BMI is an established risk factor for $\mathrm{PF}^{79}$ Weight loss may, therefore, represent an interesting approach to resolve PF. Indeed, researchers have shown that a decrease in the BMI after bariatric surgery can lead to a reduction in the frequency of clinical PF episodes. ${ }^{80}$ Other techniques for refractory PF are botulinum toxin injection, topical steroids, radiotherapy, cryosurgery, and local platelet-rich plasma injection. None of these have been shown to clearly exhibit efficacy. ${ }^{81-84}$

\section{Rarity: Infectious Plantar Fasciitis in Diabetic Foot}

Classical PF is a symptomatic, non-infectious, and local inflammation. Theoretically, diabetic foot plantar fascia can also be infected, although it is encountered very seldom in everyday clinical activities. We only found three papers in our literature search that explicitly described this clinical entity. ${ }^{85-87}$ Usually, this form of diabetic foot infection is moderate to severe, because infectious fasciitis tends to spread within a few days, if not hours. Likewise, the infection would not be limited to the plantar fascia, but also exhibit abscesses, plantar phlegmon, or cellulitis. The origin of diabetic foot plantar infections could be local trauma or injections for conventional PF. By contrast, the classical combination of ischemia and/or chronic neuropathic pressure ulcers, possibly with prior hyperkeratosis, as we have frequently encountered in the forefoot or the calcaneus, is not likely to be the origin. In infectious diabetic foot PF, a combined surgical and medical approach is mandatory from the start.

\section{Conclusion}

Adult diabetic patients are more at risk of PF than nondiabetic patients. The current evidence for management of $\mathrm{PF}$ is based mainly on retrospective and heterogonous studies and it does not exclusively address diabetic patients. The modalities for management of PF in terms of diagnosis and therapy are the same for diabetic and nondiabetic foot problems, whereas the differential diagnosis of $\mathrm{PF}$ in diabetic patients is more extensive. It is important to follow the current three-tiered approach of the American Guidelines, ${ }^{44}$ although each management should be individually tailored to the patient. None of the various diagnostic and therapeutic options is superior to another, and this also holds true for the diabetic population. Clinicians in charge of diabetic foot patients should be familiar with PF.

\section{Abbreviations}

AGEs, Advanced glycation end-products; BMI, Body mass index; ESWT, Extracorporeal shockwave therapy; MRI, Magnetic resonance imaging; NSAIDs, Nonsteroidal anti-inflammatory drugs; PF, Plantar fasciitis; 
ROM, Range of motion exercise; RCT, Randomized controlled trial; DM, Diabetes mellitus.

\section{Author Contributions}

All authors contributed to data analysis, drafting or revising the article, gave final approval of the version to be published, and agree to be accountable for all aspects of the work.

\section{Disclosure}

The authors declare that there are no conflicts of interest regarding the publication of this article.

\section{References}

1. Cho NH, Shaw JE, Karuranga S, et al. IDF diabetes atlas: global estimates of diabetes prevalence for 2017 and projections for 2045 Diabetes Res Clin Pract. 2018;138:271-281. doi:10.1016/j.diabres. 2018.02.023

2. Al-Homood IA. Rheumatic conditions in patients with diabetes mellitus. Clin Rheumatol. 2013;32(5):527-533. doi:10.1007/s10067012-2144-8

3. Ursini F, Arturi F, Nicolosi K, et al. Plantar fascia enthesopathy is highly prevalent in diabetic patients without peripheral neuropathy and correlates with retinopathy and impaired kidney function. PLoS One. 2017;12(3):e0174529. doi:10.1371/journal.pone.0174529

4. Aydeniz A, Gursoy S, Guney E. Which musculoskeletal complications are most frequently seen in type 2 diabetes mellitus? $J$ Int Med Res. 2008;36(3):505-511. doi:10.1177/147323000803600315

5. Lavery LA, Armstrong DG, Wunderlich RP, Tredwell J, Boulton AJ. Predictive value of foot pressure assessment as part of a population-based diabetes disease management program. Diabetes Care. 2003;26(4):1069-1073. doi:10.2337/diacare.26.4.1069

6. Abate M, Schiavone C, Salini V, Andia I. Occurrence of tendon pathologies in metabolic disorders. Rheumatology (Oxford). 2013;52 (4):599-608. doi:10.1093/rheumatology/kes395

7. Hernandez-Diaz C, Saavedra MA, Navarro-Zarza JE, et al. Clinical anatomy of the ankle and foot. Reumatol Clin. 2012;8(Suppl 2):46-52. doi:10.1016/j.reuma.2012.10.005

8. D'Ambrogi E, Giurato L, D'Agostino MA, et al. Contribution of plantar fascia to the increased forefoot pressures in diabetic patients. Diabetes Care. 2003;26(5):1525-1529. doi:10.2337/diacare. 26.5.1525

9. Armstrong DG, Stacpoole-Shea S, Nguyen H, Harkless LB. Lengthening of the Achilles tendon in diabetic patients who are at high risk for ulceration of the foot. J Bone Joint Surg Am. 1999;81 (4):535-538. doi:10.2106/00004623-199904000-00011

10. Frykberg RG, Lavery LA, Pham H, Harvey C, Harkless L, Veves A. Role of neuropathy and high foot pressures in diabetic foot ulceration. Diabetes Care. 1998;21(10):1714-1719. doi:10.2337/ diacare.21.10.1714

11. Gefen A. Plantar soft tissue loading under the medial metatarsals in the standing diabetic foot. Med Eng Phys. 2003;25(6):491-499. doi:10.1016/S1350-4533(03)00029-8

12. Riddle DL, Schappert SM. Volume of ambulatory care visits and patterns of care for patients diagnosed with plantar fasciitis: a national study of medical doctors. Foot Ankle Int. 2004;25 (5):303-310. doi:10.1177/107110070402500505

13. Nahin RL. Prevalence and pharmaceutical treatment of plantar fasciitis in United States adults. J Pain. 2018;19(8):885-896 doi:10.1016/j.jpain.2018.03.003
14. Priesand SJ, Schmidt BM, Ang L, et al. Plantar fasciitis in patients with type 1 and type 2 diabetes: a contemporary cohort study. J Diabetes Complications. 2019;33(10):107399. doi:10.1016/j. jdiacomp.2019.06.004

15. Taunton JE, Ryan MB, Clement DB, McKenzie DC, Lloyd-Smith DR, Zumbo BD. A retrospective case-control analysis of 2002 running injuries. $B r J$ Sports Med. 2002;36(2):95-101. doi:10.1136/ bjsm.36.2.95

16. Patel A, DiGiovanni B. Association between plantar fasciitis and isolated contracture of the gastrocnemius. Foot Ankle Int. 2011;32 (1):5-8. doi:10.3113/FAI.2011.0005

17. Riddle DL, Pulisic M, Pidcoe P, Johnson RE. Risk factors for Plantar fasciitis: a matched case-control study. $J$ Bone Joint Surg Am. 2003;85(5):872-877. doi:10.2106/00004623-200305000-00015

18. van Leeuwen KD, Rogers J, Winzenberg T, van Middelkoop M. Higher body mass index is associated with plantar fasciopathy/'plantar fasciitis': systematic review and meta-analysis of various clinical and imaging risk factors. Br J Sports Med. 2016;50(16):972-981. doi:10.1136/bjsports-2015-094695

19. Kent MJ, Light ND, Bailey AJ. Evidence for glucose-mediated covalent cross-linking of collagen after glycosylation in vitro. Biochem J. 1985;225(3):745-752. doi:10.1042/bj2250745

20. Connizzo BK, Bhatt PR, Liechty KW, Soslowsky LJ. Diabetes alters mechanical properties and collagen fiber re-alignment in multiple mouse tendons. Ann Biomed Eng. 2014;42(9):1880-1888. doi:10. 1007/s10439-014-1031-7

21. Ahmed N. Advanced glycation endproducts-role in pathology of diabetic complications. Diabetes Res Clin Pract. 2005;67(1):3-21. doi:10.1016/j.diabres.2004.09.004

22. Abate M, Schiavone C, Salini V, Andia I. Management of limited joint mobility in diabetic patients. Diabetes Metab Syndr Obes. 2013;6:197-207. doi:10.2147/DMSO.S33943

23. Waltenberger J. Impaired collateral vessel development in diabetes: potential cellular mechanisms and therapeutic implications. Cardiovasc Res. 2001;49(3):554-560. doi:10.1016/S0008-6363(00)00228-5

24. Grant WP, Sullivan R, Sonenshine DE, et al. Electron microscopic investigation of the effects of diabetes mellitus on the Achilles tendon. J Foot Ankle Surg. 1997;36(4):272-278; discussion 330. doi:10.1016/S1067-2516(97)80072-5

25. Conde J, Gomez R, Bianco G, et al. Expanding the adipokine network in cartilage: identification and regulation of novel factors in human and murine chondrocytes. Ann Rheum Dis. 2011;70(3):55 1-559. doi:10.1136/ard.2010.132399

26. Lago R, Gomez R, Otero M, et al. A new player in cartilage homeostasis: adiponectin induces nitric oxide synthase type II and pro-inflammatory cytokines in chondrocytes. Osteoarthritis Cartilage. 2008;16(9):1101-1109. doi:10.1016/j.joca.2007.12.008

27. Beason DP, Abboud JA, Kuntz AF, Bassora R, Soslowsky LJ. Cumulative effects of hypercholesterolemia on tendon biomechanics in a mouse model. J Orthop Res. 2011;29(3):380-383. doi:10.1002/ jor. 21255

28. Li C, Hsieh MC, Chang SJ. Metabolic syndrome, diabetes, and hyperuricemia. Curr Opin Rheumatol. 2013;25(2):210-216. doi:10. 1097/BOR.0b013e32835d951e

29. Schlesinger N, Thiele RG. The pathogenesis of bone erosions in gouty arthritis. Ann Rheum Dis. 2010;69(11):1907-1912. doi:10.11 36/ard.2010.128454

30. Gill LH. Plantar fasciitis: diagnosis and conservative management. J Am Acad Orthop Surg. 1997;5(2):109-117. doi:10.5435/00124635199703000-00006

31. Flanigan RM, Nawoczenski DA, Chen L, Wu H, DiGiovanni BF. The influence of foot position on stretching of the plantar fascia. Foot Ankle Int. 2007;28(7):815-822. doi:10.3113/FAI.2007.0815

32. Veves A, Murray HJ, Young MJ, Boulton AJ. The risk of foot ulceration in diabetic patients with high foot pressure: a prospective study. Diabetologia. 1992;35(7):660-663. doi:10.1007/BF00400259 
33. Pataky Z, Assal JP, Conne P, Vuagnat H, Golay A. Plantar pressure distribution in Type 2 diabetic patients without peripheral neuropathy and peripheral vascular disease. Diabet Med. 2005;22(6):762-767. doi:10.1111/j.1464-5491.2005.01520.x

34. Pataky Z, Golay A, Faravel L, et al. The impact of callosities on the magnitude and duration of plantar pressure in patients with diabetes mellitus. A callus may cause 18,600 kilograms of excess plantar pressure per day. Diabetes Metab. 2002;28(5):356-361.

35. Ctercteko GC, Dhanendran M, Hutton WC, Le Quesne LP. Vertical forces acting on the feet of diabetic patients with neuropathic ulceration. Br J Surg. 1981;68(9):608-614. doi:10.1002/bjs.180068 0904

36. Shaw JE, van Schie CH, Carrington AL, Abbott CA, Boulton AJ. An analysis of dynamic forces transmitted through the foot in diabetic neuropathy. Diabetes Care. 1998;21(11):1955-1959. doi:10.2337/ diacare.21.11.1955

37. Gariani K, Uckay I, Lipsky BA. Managing diabetic foot infections: a review of the new guidelines. Acta Chir Belg. 2014;114(1):7-16. doi:10.1080/00015458.2014.11680970

38. Levy JC, Mizel MS, Clifford PD, Temple HT. Value of radiographs in the initial evaluation of nontraumatic adult heel pain. Foot Ankle Int. 2006;27(6):427-430. doi:10.1177/107110070602700607

39. Osborne HR, Breidahl WH, Allison GT. Critical differences in lateral X-rays with and without a diagnosis of plantar fasciitis. $J$ Sci Med Sport. 2006;9(3):231-237. doi:10.1016/j.jsams.2006.03.028

40. Alshami AM, Souvlis T, Coppieters MW. A review of plantar heel pain of neural origin: differential diagnosis and management. Man Ther. 2008;13(2):103-111. doi:10.1016/j.math.2007.01.014

41. Zhou B, Zhou Y, Tao X, Yuan C, Tang K. Classification of calcaneal spurs and their relationship with plantar fasciitis. J Foot Ankle Surg. 2015;54(4):594-600. doi:10.1053/j.jfas.2014.11.009

42. Chimutengwende-Gordon M, O'Donnell P, Singh D. Magnetic resonance imaging in plantar heel pain. Foot Ankle Int. 2010;31 (10):865-870. doi:10.3113/FAI.2010.0865

43. Draghi F, Gitto S, Bortolotto C, Draghi AG, Ori Belometti G. Imaging of plantar fascia disorders: findings on plain radiography, ultrasound and magnetic resonance imaging. Insights Imaging. 2017;8(1):69-78. doi:10.1007/s13244-016-0533-2

44. Thomas JL, Christensen JC, Kravitz SR, et al. The diagnosis and treatment of heel pain: a clinical practice guideline-revision 2010 . J Foot Ankle Surg. 2010;49(3 Suppl):S1-19. doi:10.1053/j.jfas.20 10.01 .001

45. Uckay I, Gariani K, Dubois-Ferriere V, Suva D, Lipsky BA. Diabetic foot infections: recent literature and cornerstones of management. Curr Opin Infect Dis. 2016;29(2):145-152. doi:10.1097/QCO.0000 000000000243

46. Uckay I, Jornayvaz FR, Lebowitz D, Gastaldi G, Gariani K, Lipsky BA. An overview on diabetic foot infections, including issues related to associated pain, hyperglycemia and limb ischemia. Curr Pharm Des. 2018;24(12):1243-1254. doi:10.2174/13816128246661 80302145754

47. Francia P, Gulisano M, Anichini R, Seghieri G. Diabetic foot and exercise therapy: step by step the role of rigid posture and biomechanics treatment. Curr Diabetes Rev. 2014;10(2):86-99. doi:10.2174/1573399810666140507112536

48. Gardner AW, Poehlman ET. Exercise rehabilitation programs for the treatment of claudication pain. A meta-analysis. JAMA. 1995;274 (12):975-980. doi:10.1001/jama.1995.03530120067043

49. Balducci S, Zanuso S, Cardelli P, et al. Supervised exercise training counterbalances the adverse effects of insulin therapy in overweight/ obese subjects with type 2 diabetes. Diabetes Care. 2012;35 (1):39-41. doi:10.2337/dc11-1450

50. Tucker PS, Fisher-Wellman K, Bloomer RJ. Can exercise minimize postprandial oxidative stress in patients with type 2 diabetes? Curr Diabetes Rev. 2008;4(4):309-319. doi:10.2174/157339908786241 160
51. Giacomozzi C, D’Ambrogi E, Uccioli L, Macellari V. Does the thickening of Achilles tendon and plantar fascia contribute to the alteration of diabetic foot loading? Clin Biomech (Bristol, Avon). 2005;20(5):532-539. doi:10.1016/j.clinbiomech.2005.01.011

52. Cerrahoglu L, Kosan U, Sirin TC, Ulusoy A. Range of motion and plantar pressure evaluation for the effects of self-care foot exercises on diabetic patients with and without neuropathy. $J$ Am Podiatr Med Assoc. 2016;106(3):189-200. doi:10.7547/14-095

53. Goldsmith JR, Lidtke RH, Shott $\mathrm{S}$. The effects of range-of-motion therapy on the plantar pressures of patients with diabetes mellitus. J Am Podiatr Med Assoc. 2002;92(9):483-490. doi:10.7547/875 07315-92-9-483

54. Sweeting D, Parish B, Hooper L, Chester R. The effectiveness of manual stretching in the treatment of plantar heel pain: a systematic review. J Foot Ankle Res. 2011;4:19. doi:10.1186/1757-1146-4-19

55. Donley BG, Moore T, Sferra J, Gozdanovic J, Smith R. The efficacy of oral nonsteroidal anti-inflammatory medication (NSAID) in the treatment of plantar fasciitis: a randomized, prospective, placebo-controlled study. Foot Ankle Int. 2007;28(1):20-23. doi:10. 3113/FAI.2007.0004

56. Schepsis AA, Leach RE, Gorzyca J. Plantar fasciitis. Etiology, treatment, surgical results, and review of the literature. Clin Orthop Relat Res. 1991;266:185-196.

57. Gill LH, Kiebzak GM. Outcome of nonsurgical treatment for plantar fasciitis. Foot Ankle Int. 1996;17(9):527-532. doi:10.1177/107110 079601700903

58. Crawford F, Atkins D, Young P, Edwards J. Steroid injection for heel pain: evidence of short-term effectiveness. A randomized controlled trial. Rheumatology (Oxford). 1999;38(10):974-977. doi:10.1093/ rheumatology/38.10.974

59. Acevedo JI, Beskin JL. Complications of plantar fascia rupture associated with corticosteroid injection. Foot Ankle Int. 1998;19 (2):91-97. doi:10.1177/107110079801900207

60. Sellman JR. Plantar fascia rupture associated with corticosteroid injection. Foot Ankle Int. 1994;15(7):376-381. doi:10.1177/107110 079401500706

61. Rasenberg N, Riel H, Rathleff MS, Bierma-Zeinstra SMA, van Middelkoop M. Efficacy of foot orthoses for the treatment of plantar heel pain: a systematic review and meta-analysis. $\mathrm{Br} J$ Sports Med. 2018;52(16):1040-1046. doi:10.1136/bjsports-2017-097892

62. Wheeler PC. The addition of a tension night splint to a structured home rehabilitation programme in patients with chronic plantar fasciitis does not lead to significant additional benefits in either pain, function or flexibility: a single-blinded randomised controlled trial. BMJ Open Sport Exerc Med. 2017;3(1):e000234. doi:10.1136/ bmjsem-2017-000232

63. Tisdel CL, Harper MC. Chronic plantar heel pain: treatment with a short leg walking cast. Foot Ankle Int. 1996;17(1):41-42. doi: $10.1177 / 107110079601700109$

64. Shikoff MD, Figura MA, Postar SE. A retrospective study of 195 patients with heel pain. $J$ Am Podiatr Med Assoc. 1986;76(2):71-75. doi:10.7547/87507315-76-2-71

65. Davis PF, Severud E, Baxter DE. Painful heel syndrome: results of nonoperative treatment. Foot Ankle Int. 1994;15(10):531-535. doi: $10.1177 / 107110079401501002$

66. Daly PJ, Kitaoka HB, Chao EY. Plantar fasciotomy for intractable plantar fasciitis: clinical results and biomechanical evaluation. Foot Ankle. 1992;13(4):188-195. doi:10.1177/107110079201300 404

67. Fallat LM, Cox JT, Chahal R, Morrison P, Kish J. A retrospective comparison of percutaneous plantar fasciotomy and open plantar fasciotomy with heel spur resection. J Foot Ankle Surg. 2013;52 (3):288-290. doi:10.1053/j.jfas.2012.10.005

68. Oliva F, Piccirilli E, Tarantino U, Maffulli N. Percutaneous release of the plantar fascia. New surgical procedure. Muscles Ligaments Tendons J. 2017;7(2):338-340. doi:10.11138/mltj/2017.7.2.338 
69. Catal B, Keskinbora M, Uysal MA, Sahin M, Gulabi D, Demiralp B. Endoscopic plantar fasciotomy; deep fascial versus superficial fascial approach: a prospective randomized study. J Foot Ankle Surg. 2017;56(5):1001-1008. doi:10.1053/j.jfas.2017.04.021

70. Chou AC, Ng SY, Su DH, Singh IR, Koo K. Radiofrequency microtenotomy is as effective as plantar fasciotomy in the treatment of recalcitrant plantar fasciitis. Foot Ankle Surg. 2016;22(4):270-273. doi:10.1016/j.fas.2015.11.006

71. Barrett SJ, O'Malley R. Plantar fasciitis and other causes of heel pain. Am Fam Physician. 1999;59(8):2200-2206.

72. Kinley S, Frascone S, Calderone D, Wertheimer SJ, Squire MA, Wiseman FA. Endoscopic plantar fasciotomy versus traditional heel spur surgery: a prospective study. J Foot Ankle Surg. 1993;32(6):595-603.

73. Al-Mayahi M, Cian A, Kressmann B, et al. Associations of diabetes mellitus with orthopaedic infections. Infect Dis (Lond). 2016;48 (1):70-73. doi:10.3109/23744235.2015.1082620

74. Wu YH, Lun JJ, Chen WS, Chong FC. The electrophysiological and functional effect of shock wave on peripheral nerves. Conf Proc IEEE Eng Med Biol Soc. 2007;2007:2369-2372. doi:10.1109/ IEMBS.2007.4352803

75. Mariotto S, de Prati AC, Cavalieri E, Amelio E, Marlinghaus E, Suzuki H. Extracorporeal shock wave therapy in inflammatory diseases: molecular mechanism that triggers anti-inflammatory action. Curr Med Chem. 2009;16(19):2366-2372. doi:10.2174/092986709788682119

76. Dizon JN, Gonzalez-Suarez C, Zamora MT, Gambito EDRE. Effectiveness of extracorporeal shock wave therapy in chronic plantar fasciitis. Am J Phys Med Rehabil. 2014;93(8):735. doi:10.1097/ PHM.0000000000000121

77. Steffens D, Maher CGRE. Effectiveness of extracorporeal shock wave therapy in chronic plantar fasciitis. Am J Phys Med Rehabil. 2014;93(5):458-459. doi:10.1097/PHM.0000000000000061

78. Mardani-Kivi M, Karimi Mobarakeh M, Hassanzadeh Z, et al. Treatment outcomes of corticosteroid injection and extracorporeal shock wave therapy as two primary therapeutic methods for acute plantar fasciitis: a prospective randomized clinical trial. J Foot Ankle Surg. 2015;54(6):1047-1052. doi:10.1053/j.jfas.2015.04.026
79. Abate M, Schiavone C, Di Carlo L, Salini V. Achilles tendon and plantar fascia in recently diagnosed type II diabetes: role of body mass index. Clin Rheumatol. 2012;31(7):1109-1113. doi:10.1007/ s10067-012-1955-y

80. Boules M, Batayyah E, Froylich D, et al. Effect of surgical weight loss on plantar fasciitis and health-care use. J Am Podiatr Med Assoc. 2018;108(6):442-448. doi:10.7547/15-169

81. Thomson CE, Crawford F, Murray GD. The effectiveness of extra corporeal shock wave therapy for plantar heel pain: a systematic review and meta-analysis. BMC Musculoskelet Disord. 2005;6:19. doi:10.1186/1471-2474-6-19

82. Babcock MS, Foster L, Pasquina P, Jabbari B. Treatment of pain attributed to plantar fasciitis with botulinum toxin a: a short-term, randomized, placebo-controlled, double-blind study. Am J Phys Med Rehabil. 2005;84(9):649-654. doi:10.1097/01.phm.0000176339.735 91.d7

83. Vahdatpour B, Mokhtarian A, Raeissadat SA, Dehghan F, Nasr N, Mazaheri M. Enhancement of the effectiveness of extracorporeal shock wave therapy with topical corticosteroid in treatment of chronic plantar fasciitis: a randomized control clinical trial. $A d v$ Biomed Res. 2018;7:62. doi:10.4103/abr.abr 4017

84. Macias DM, Coughlin MJ, Zang K, Stevens FR, Jastifer JR, Doty JF. Low-level laser therapy at $635 \mathrm{~nm}$ for treatment of chronic plantar fasciitis: a placebo-controlled, randomized study. J Foot Ankle Surg. 2015;54(5):768-772. doi:10.1053/j.jfas.2014.12.014

85. Wronka KS, Sinha A. Calcaneal osteomyelitis following steroid injection for plantar fasciitis: a case report. Foot Ankle Spec. 2012;5(4):253-255. doi:10.1177/1938640012451313

86. Aragon-Sanchez J, Lazaro-Martinez JL, Pulido-Duque J, Maynar M. From the diabetic foot ulcer and beyond: how do foot infections spread in patients with diabetes? Diabet Foot Ankle. 2012;3.

87. Mismar A, Yousef M, Badran D, Younes N. Ascending infection of foot tendons in diabetic patients. Int J Low Extrem Wounds. 2013;12 (4):271-275. doi:10.1177/1534734613493290

\section{Publish your work in this journal}

Diabetes, Metabolic Syndrome and Obesity: Targets and Therapy is an international, peer-reviewed open-access journal committed to the rapid publication of the latest laboratory and clinical findings in the fields of diabetes, metabolic syndrome and obesity research. Original research, review, case reports, hypothesis formation, expert opinion and commentaries are all considered for publication. The manuscript management system is completely online and includes a very quick and fair peer-review system, which is all easy to use. Visit http://www.dovepress.com/testimonials.php to read real quotes from published authors. 